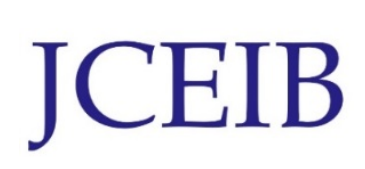

Journal Chemical Engineering and Industrial Biotechnology (JCEIB) Open Access

Volume 2 pp. 27-36; September 2017

(C) Universiti Malaysia Pahang Publisher

DOI: https://doi.org/10.15282/JCEIB-V2-01.29/9/2017/2.2

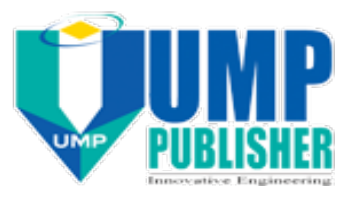

\title{
OPTIMIZATION OF GLYCEROL RECOVERY FROM PRETREATMENT PROCESS TO PRODUCE SUCCINIC ACID VIA ANAEROBIC FERMENTATION
}

\author{
Nik Nor Aziati Abdul Aziz ${ }^{\mathrm{a}}$, Mimi Sakinah Abdul Munaim ${ }^{\mathrm{b}^{*}}$ \\ ${ }^{a}$ Faculty of Engineering Technology, Universiti of Malaysia Pahang, Lebuhraya Tun Razak, 26300 \\ Kuantan, Pahang, Malaysia \\ ${ }^{\text {b* }}$ Faculty of Chemical and Natural Resources Engineering, Universiti Malaysia Pahang, Lebuhraya Tun \\ Razak, 26300Kuantan, Pahang, Malaysia \\ * Corresponding author: E-mail: mimisakinah@gmail.com \\ Tel: +609 5492031/2825; Fax: +6095492662
}

\begin{abstract}
This study aims to produce succinic acid from glycerol residue through anaerobic fermentation process. The optimum condition of $\mathrm{pH}$, mass substrate, and temperature was determined using response surface methodology (RSM). The concentration of glycerol and succinic acid were determined using HPLC analysis. The FTIR spectrometry was applied to examine the adsorption of organic element. Optimization of fermentation condition using RSM yielded glycerol of $159.312 \mathrm{~g} / \mathrm{L}$ at $\mathrm{pH} 2,35^{\circ} \mathrm{C}$, and $110.36 \mathrm{~g}$ of substrate. Succinic acid was the product of fermentation by Escherichia coli type k-12 under $19.67 \mathrm{~g} / \mathrm{L}$ initial glycerol concentration, $200 \mathrm{rpm}$ rotational speed, and $37^{\circ} \mathrm{C}$. The fermentation with treated glycerol generated $0.66983 \mathrm{~g} / \mathrm{L}$ of succinic acid, compared to commercial glycerol which generated $0.73337 \mathrm{~g} / \mathrm{L}$ of succinic acid. Overall, this research show that glycerol waste can be used as the carbon source to produce succinic acid by implementing fermentation of Escherichia coli type k-12. From the fermentation process, succinic acid was not the major product. Further study in genetic modification of Escherichia coli is highly suggested to produce succinic acid as the major product, as well as to improve the fermentation process.
\end{abstract}

Keywords: Glycerol, Glycerol residue, Glycerol pitch, Recovered glycerol production; Glycerol waste pre-treatment, pre-treatment process.

\subsection{INTRODUCTION}

Over the last decade, succinic acid has attracted attention worldwide with its excellent characteristic as an additive in products (Agarwal et al., 2005). Succinic acid is commonly produced from liquefied petroleum gas or petroleum oil as the starting material via chemical processes (Song and Lee, 2006). Therefore, it can cause potential hazard and environmental pollution as the impact of succinic acid production via chemical synthesis route. Succinic acid can also be produced through fermentation process using microorganism and glycerol as the substrate (Lee et al., 2000).

The fermentation process utilises glycerol as the carbon source, thereby reducing the potential of by-products generation such as acetic acid that will negatively affect the purification process (Lee et al., 2000). The production of succinic acid using glycerol 
waste from palm-based oleochemical industry is attractive due to the abundance of glycerol source (Hazimah et al., 2003).

Furthermore, by utilizing renewable resources as fermentation medium is more costeffective as it does not involve petroleum-based processes (Zeikus et al., 1999). In an anaerobic fermentation, succinic acid is one of the by-products. Hence, attempts have been made worldwide to screen anaerobic microorganisms for succinic acid production in large scale (Dikshit and Moholkar, 2016). The study is focus on the pre-treatment and fermentation process to produce succinic acid. The experiment developed will able to explain the process of succinic acid production. This study also discusses the conversion of glycerol into high value products under anaerobic condition.

\subsection{MATERIAL AND METHOD}

Glycerol residue was obtained from Emery Oleochemical Sdn. Bhd. Analytical grade of sulfuric acid, sodium hydroxide, methanol (98\% purity), and glycerol were used in this research.

\section{Esterification}

Esterification process is the conversion of carboxylic acid to ester using acid and alcohol. The amount of glycerol residue $(30 \mathrm{~g}, 60 \mathrm{~g}, 90 \mathrm{~g}, 120 \mathrm{~g}$ and $150 \mathrm{~g})$ was diluted with $150 \mathrm{~mL}$ of distilled water. Then, the mixture was heated and stirred in a reaction flask at the same speed for all test runs for $5 \mathrm{~min}$ to ensure complete dilution of glycerol residue and water. After that, the $\mathrm{pH}$ of the solution was adjusted to desired $\mathrm{pH}$ in the range of 1 to 5 using concentrated sulphuric acid $\left(\mathrm{H}_{2} \mathrm{SO}_{4}\right)$. Then, the mixture was allowed to settle until two distinct layers were visible. The top layer of fatty acid containing tar such as solid waste and salt residue was removed using slow decantation. The aqueous layer was filtered to further remove any solid materials and other charred substances that remained in the mixture.

\section{Alkali-Catalysed Transesterification}

Alkali-catalysed transesterification using alkali to catalyst the products. By removing the residue salts from the glycerol-rich layer, the solution was neutralised by adding $5 \mathrm{M}$ $\mathrm{NaOH}$ until $\mathrm{pH} 7.0$ was obtained. Later, the solution was left for a while prior to filtering once again to eliminate the precipitated salt. After the separation process, ether extracts were combined and concentrated using a rotary evaporator to remove residual water. During this extraction process, the temperature of the water bath was set to $105^{\circ} \mathrm{C}$ for 2 $\mathrm{h}$. After the evaporation process, the methanol-to-crude glycerol ratio (v/v) were added at a ratio of $2: 1$ to the mixture. The mixture was allowed to stand at room temperature for 30 min to cool, followed by refrigeration for another $30 \mathrm{~min}$ to ensure a complete precipitation of the salt in the mixture. The precipitated inorganic salt was filtered and washed with chilled methanol. After the crude glycerol was recovered, the methanol in the mixture was eliminated using a rotary evaporator and heated in a silicon oil bath at 80 ${ }^{\circ} \mathrm{C}$ for $20 \mathrm{~min}$ to recover a pure crude glycerol (Darnoko and Cheryan, 2000).

\section{Fermentation Process}

Succinic acid is the principal product in the anaerobic fermentation of glycerol. In the preliminary study, the pre-treatment processes (esterification and alkali-catalysed transesterification) were utilised to recover glycerol, and subsequently the process continued with the fermentation process to produce succinic acid. This fermentation 
process was tested with two different substrates which were the treated glycerol from the oleochemical company and a commercial grade glycerol. The results were compared with a treated glycerol from a biodiesel company which had undergone fermentation in a similar manner. The profile growth of Escherichia coli type K-12 cultured in $20 \mathrm{~g} / \mathrm{L}$ of treated glycerol as the carbon source under anaerobic condition and the medium was supplemented with $10 \mathrm{~g} / \mathrm{L}$ of tryptone. About $10 \%$ of working volume of inoculum was added to the medium for profile growth process. Table 1 shows the reaction variables for the fermentation process.

Table 1: The reaction variables for the fermentation process.

\begin{tabular}{ccc} 
Numbers & Reaction Variables & Value \\
\hline 1 & Glycerol concentration $(\mathrm{g} / \mathrm{l})$ & 19.67 \\
2 & Tryptone concentration $(\mathrm{g} / \mathrm{l})$ & 12.19 \\
3 & $\mathrm{Na}_{2} \mathrm{SO}_{3}$ concentration $(\mathrm{g} / \mathrm{l})$ & 1.0 \\
4 & Incubation period $(\mathrm{h})$ & 63.8 \\
5 & Inoculum density $(\%)$ & 4.0 \\
6 & $\mathrm{pH}$ & 6.88 \\
\hline
\end{tabular}

\section{HPLC analysis}

The glycerol and succinic acid was determined by using high performance liquid chromatography (HPLC) analysis. The type of high performance liquid chromatography equipment used was the HPLC-1200 Agilent Technologies with Reflective Index detector (RI) and the type of column was Aminex HPX-87H; $300 \mathrm{~mm} \times 7.8000 \mathrm{~mm}, 9 \mu \mathrm{m}$; manufactured by Bio-Rad Chemical Division, CA., USA. The operating temperature was about $50{ }^{\circ} \mathrm{C}$ and the mobile phase used was $0.0005 \mu \mathrm{m}$ sulfuric acid $\left(\mathrm{H}_{2} \mathrm{SO}_{4}\right)$ solution. The flow rate was controlled at $0.6000 \mathrm{ml} / \mathrm{min}$ (Agarwal et al., 2005).

\section{Optimization of Parameters}

Response surface methodology based on face-centred central composite design (FCCCD) under Design-Expert software (version 6.0.8, Stat-Ease, Minneapolis, USA) was used to optimise the fermentation condition $(\mathrm{pH}$, temperature and mass substrate (glycerol residue)to obtain the highest amount of glycerol. The data was fitted to a polynomial equation to obtain a regression equation. The statistical significance at $95 \%$ confidence in terms of regression equation was examined by analysis of variance (ANOVA). Response surface plots were generated by the software. The average concentration of sugar mixture from a duplicate determination was used as a response(Rashid and Anwar, 2008).

\subsection{RESULTS AND DISCUSSION}

Response surface methodology (RSM) based on face-centred central composite design (FCCCD) was applied to determine the effects of operational parameters ( $\mathrm{pH}$, temperature and mass substrate) on the recovery of glycerol from its residue in the pretreatment process. Twenty-eight experimental runs which correspond to varying parameters $(\mathrm{pH}$, temperature and substrate concentration) were carried out in the pretreatment process. The effects of these parameters on glycerol recovery from its residue were evaluated. 


\section{Analysis of variance (ANOVA)}

Statistical analysis of the results shows that the optimum parameter combination is at 35 ${ }^{\circ} \mathrm{C}, 110 \mathrm{~g}$ of substrate (glycerol residue), and $\mathrm{pH}$ 1.5. Under this optimum condition, $159.414 \mathrm{~g} / \mathrm{L}$ of glycerol concentration was obtained. The second order regression model shows the relationship between the response (glycerol concentration) and operating parameters of $\mathrm{pH}(\mathrm{A})$, temperature (B), and substrate (C). The regression model analysis is shown in Eq. (1):

Final Equation in Terms of Actual Factors:

$$
\begin{aligned}
\text { Glycerol Concentration }= & +46.0394+80.9362 * \mathrm{pH}+5.2028 * \text { Temperature } \\
& -1.15086^{*} \text { Substrate }(\text { Glycerol residue })+0.0802 * \\
& \text { Temperature }+0.0198 * \text { Substrate }(\text { Glycerol residue })_{2} \\
& -0.6268^{*} \mathrm{pH} * \text { Substrate }(\text { Glycerol residue })- \\
& 0.0788^{*} \text { Temperature } * \text { Substrate }(\text { Glycerol residue })
\end{aligned}
$$

In order to establish a good response from the model, three tests were performed which were the significance of regression model, significance on individual coefficient, and the lack-of-fit. Fisher's statistical test for ANOVA was employed to verify the determination of coefficient $\left(\mathrm{R}^{2}\right)$ and adequacy of the model by determining the significance of variable according to the value of F-ratio. It was found that the confidence level was greater than $95 \%(p<0.05)$ for glycerol recovery. The $F$-value of the model was $12.26(p<0.0001)$ which implies its significance. In the similar manner, the main effects of $\mathrm{pH}(\mathrm{A})$, temperature $(B)$, substrate $(C)$, second order effect of temperature $\left(B^{2}\right)$, second order effects of substrate $\left(\mathrm{C}^{2}\right)$, the two-level interaction of $\mathrm{pH}$ and substrate $(\mathrm{AC})$, and the twolevel interaction of temperature and substrate $(\mathrm{BC})$ were also significant as model factors.

The determination of coefficient $\left(\mathrm{R}^{2}\right)$ for this model was 0.8346 indicating that $83.46 \%$ variation could be explained by the model equation. A better correlation between the observed and the predicted value was indicated by the nearest $R^{2}$ value to $1 . R^{2}$ is used to decide whether the regression model is appropriate or not by measuring the amount of variation around the mean being explained by the model. If the residual value increased, the $\mathrm{R}^{2}$ decreased in the range 1 to 0 . Residual is the difference between the observed value and the fitted value. The value adjusted $\mathrm{R}^{2}$ (Adj $\mathrm{R}^{2}$ ) of this model was $0.7665(76.65 \%)$ while Pre R-squared was $0.6202(62.02 \%)$. Adj $R^{2}$ is a measure of the amount of variation in the dependent variables for which the model took into account, and it will adjust the $\mathrm{R}^{2}$ based on the number coefficient in the model.

In general, the value of lack-of-fit is to indicate the insignificance in the pure error (Isar et al., 2006a). It is calculated using the ratio between the mean square of the model error. For this model, the lack-of-fit is 0.8786 which implies $87.86 \%$ chance that lack-of-fit would occur due to the noise. It appears that the represented model is desirably fit. Significant effect on the response was further analysed and diagnosed.

The normal probability plot of residual and the plot of residual versus predicted response for glycerol recovery are shown in Figures 1.0 and 2.0. Based on Figure 1.0, the residual falls on the straight line implying that the errors are distributed normally and support the adequacy of least-square fit. In addition, Figure 2.0 reveals no obvious pattern and 
unusual structure. It shows that the plots are almost equally scattered above and below the $\mathrm{x}$-axis and uniformly tabulated within the red lines of the x-axis. This means that the proposed model is adequate and there is no reason to suspect any violation of the independence or constant variance assumption. Figure 3.0 shows the outlier-t plot response for glycerol concentration. The data plots reveal that the plots are within the red lines of the $\mathrm{x}$-axis, thereby indicating that the data obtained are located within the prediction range.

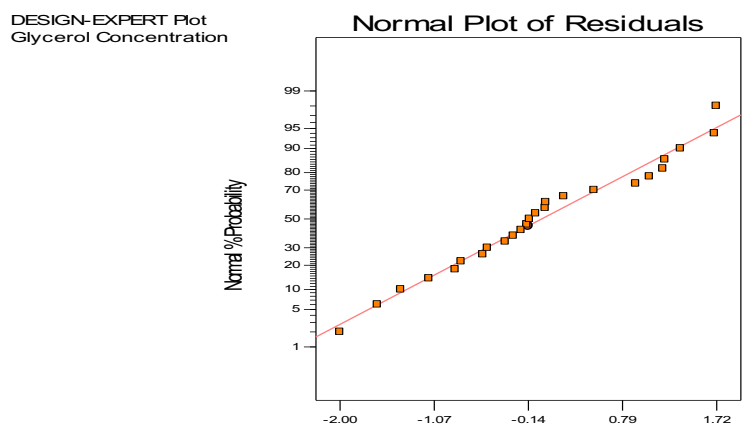

Studentized Residuals

Figure 1: Normal probability plot of residual for glycerol concentration

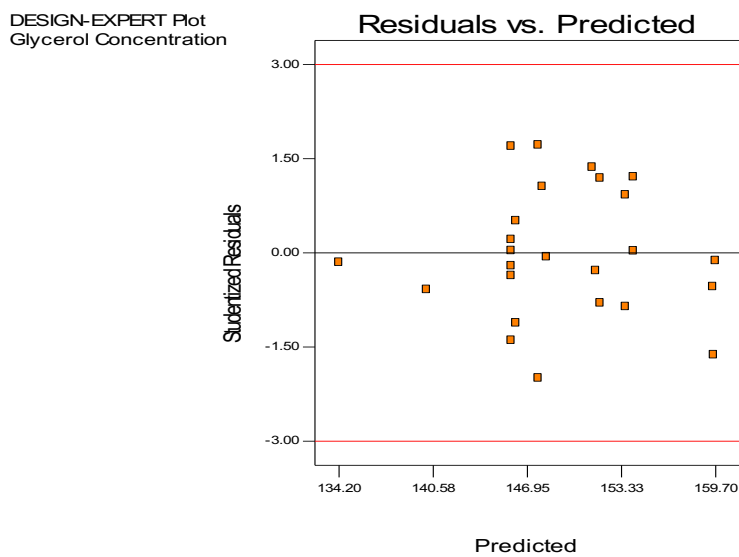

Figure 2: Residual versus predicted response for glycerol concentration

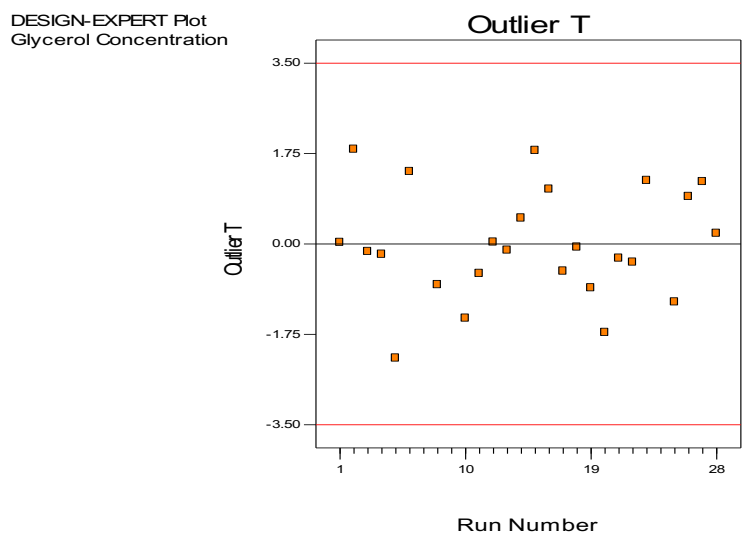

Figure 3: Outlier-t plot response for glycerol concentration 


\section{Interaction of different operating parameters}

The three-dimensional response surface curve is used to study the interaction among different factors used and to find the optimum condition for maximum recovery of glycerol (Isar et al., 2006b). Figure 4.0 shows the 3D response surface graph for the interaction between $\mathrm{pH}$ and temperature in glycerol recovery. Meanwhile, Figure 5.0 shows the interaction effect graph between $\mathrm{pH}$ and temperature. It can be seen that the temperature range was from 25 to $35^{\circ} \mathrm{C}$ and the $\mathrm{pH}$ was from 1 to 2 which corresponds to a maximum glycerol concentration of $153.552 \mathrm{~g} / \mathrm{L}$. Jansri et al. (2011), had evaluated the temperature as a parameter for methyl ester production from mixed crude palm oil by using acid-alkali catalyst. The temperatures used for their study were 55, 60, and $65^{\circ} \mathrm{C}$. Another work by Stamenkovitc et al. (2008) reported the use of low temperature (10-30 ${ }^{\circ} \mathrm{C}$ ) in sunflower oil methanolys is process.

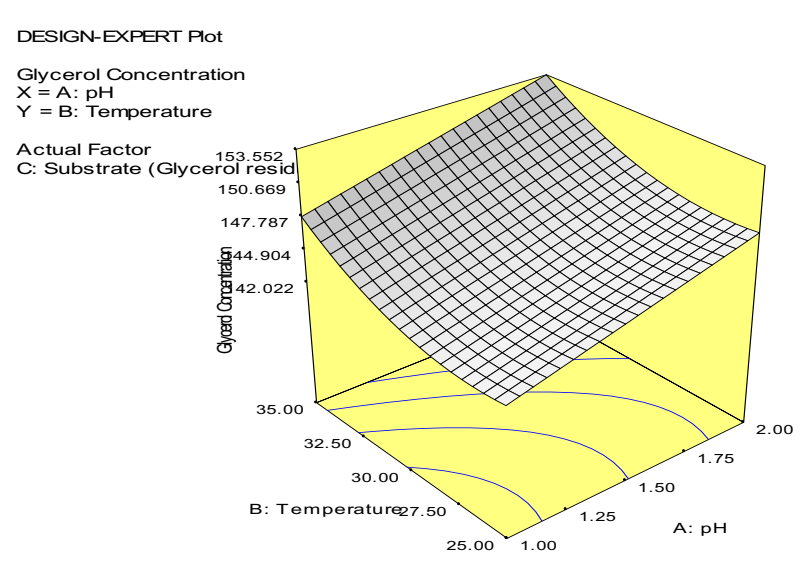

Figure 4: 3D surface response graph for interaction between $\mathrm{pH}$ and temperature

The interaction between $\mathrm{pH}$ and substrate analysis in terms of the $3 \mathrm{D}$ response surface curve is shown in Figure 5.0, and the interaction effect graph is exhibited in Figure 6.0. The A plot represents $\mathrm{pH}$ and $\mathrm{C}$ plot represents the substrate. The $3 \mathrm{D}$ response surface curve implies a relative interaction between $\mathrm{pH}$ and substrate (glycerol residue) which corresponds to $151.02 \mathrm{~g} / \mathrm{L}$ of glycerol concentration. Yong et al.(2001) used $\mathrm{pH}$ less than 5 to avoid foaming in refining of crude glycerine recovered from glycerol residue.

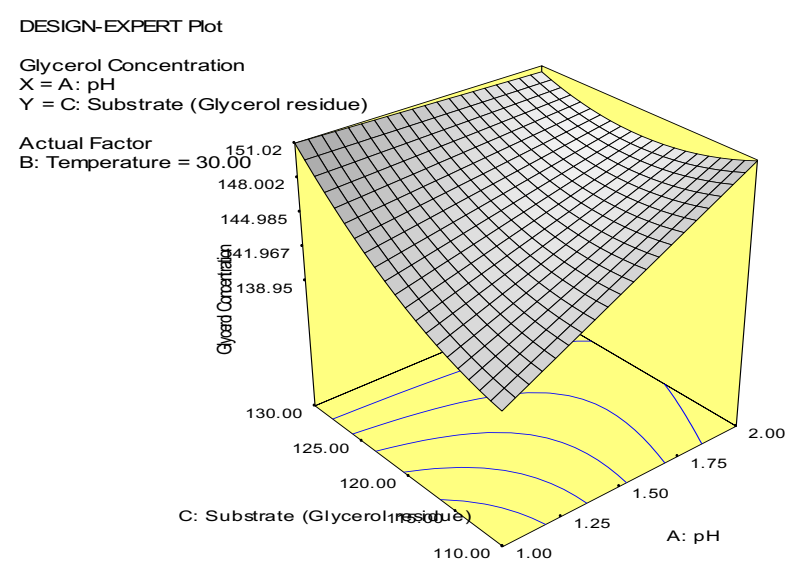

Figure 5: 3D surface response graph for interaction between $\mathrm{pH}$ and substrate 


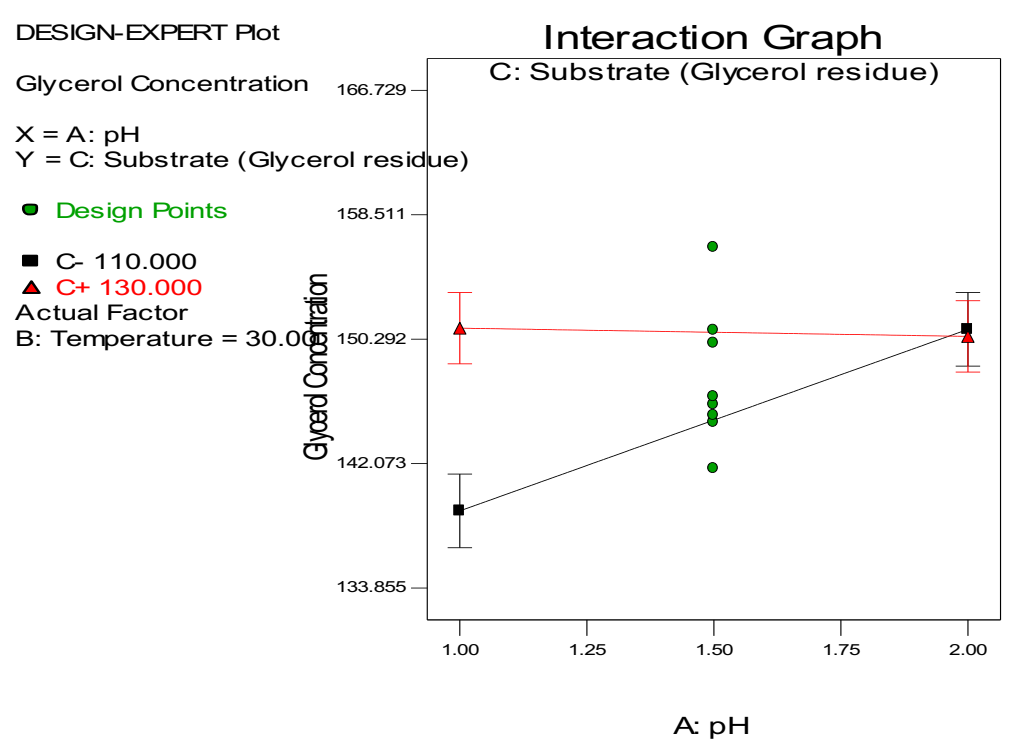

Figure 6: Interaction effect graph between $\mathrm{pH}$ and substrate

The interaction between temperature (B) and substrate (C) was examined from 25 to 35 ${ }^{\circ} \mathrm{C}$ and 110 to $130 \mathrm{~g}$ of glycerol residue as the substrate. Figure 7.0 shows the $3 \mathrm{D}$ surface response graph for the interaction between temperature and substrate in glycerol recovery, while Figure 8.0 displays the interaction effect between the two parameters. From the 3D response curve, the maximum glycerol concentration was found to be $153.881 \mathrm{~g} / \mathrm{L}$. Hayyan et al.(2011) studied the reduction of high content of free fatty acid in palm oil sludge via acid catalyst to produce biodiesel and found that the temperature was played an important role in the transesterification process. Their optimum temperature for the study was $60^{\circ} \mathrm{C}$.

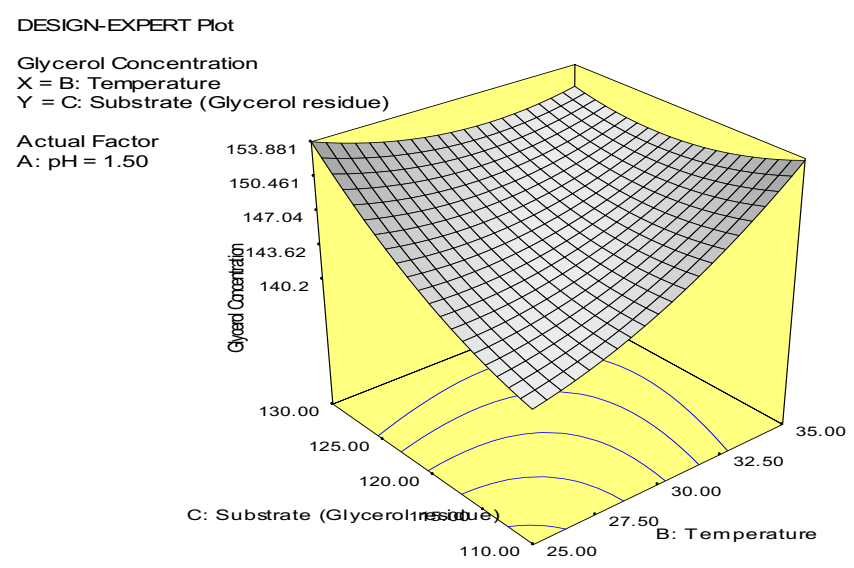

Figure 7: 3D surface response curve for the interaction between temperature and substrate 


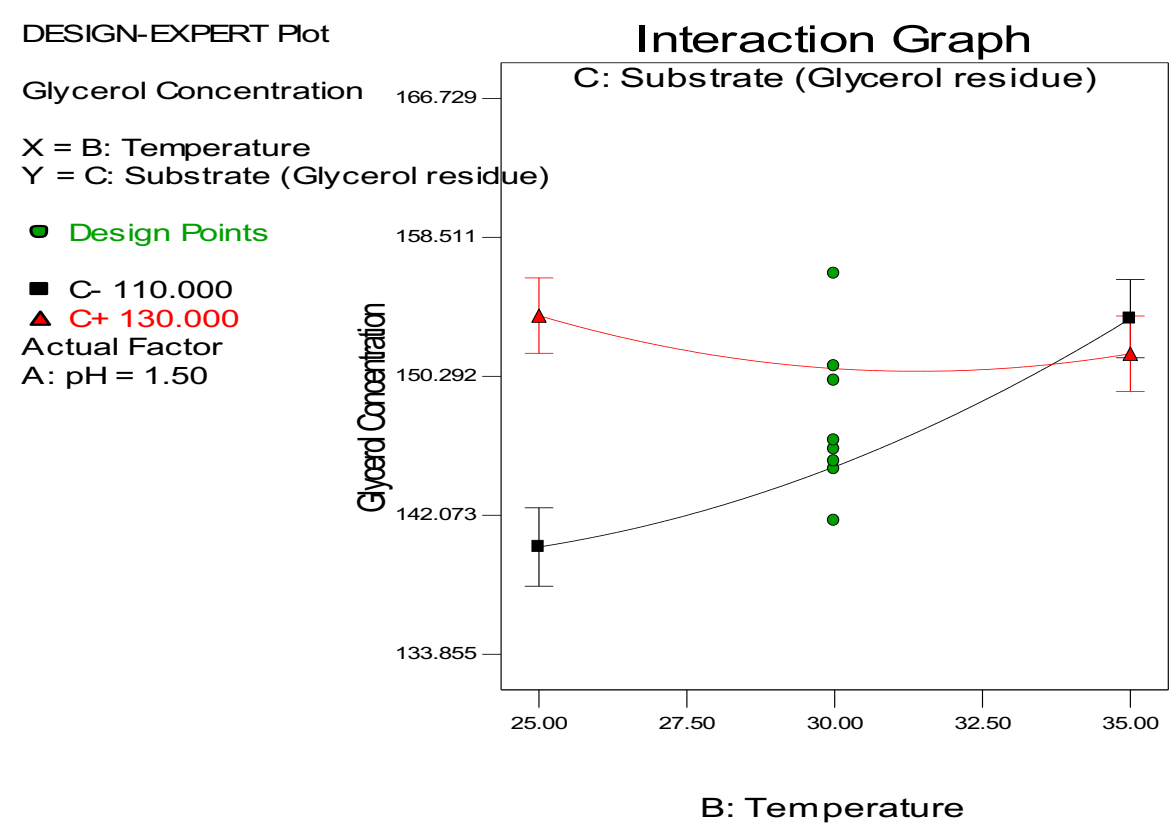

Figure 8: Interaction effect graph between temperature and substrate

\section{Validation}

In order to validate the adequacy of the model, five confirmation runs were performed and the observed results were compared with the predicted results. The condition for each run is listed in Table 2.0.

Table 2: The percentage error between the actual and predicted value for treated glycerol.

\begin{tabular}{cccccccc}
\hline \multirow{2}{*}{$\begin{array}{c}\text { Number } \\
\text { of run }\end{array}$} & \multicolumn{3}{c}{ Run Factor } & \multicolumn{3}{c}{ Glycerol production (g/L) } \\
\cline { 2 - 8 } & $\mathbf{p H}$ & Temp & Substrate & Actual & Predicted & Residual & $\begin{array}{c}\text { Error } \\
\text { (\%) }\end{array}$ \\
\hline 1 & 2 & 35 & 110.36 & 159.414 & 159.312 & 0.102 & 0.064 \\
2 & 2 & 35 & 110.28 & 159.473 & 160.107 & -0.634 & 0.398 \\
3 & 2 & 35 & 110.06 & 159.652 & 160.317 & -0.665 & 0.417 \\
4 & 2 & 35 & 110.00 & 159.622 & 161.617 & -1.995 & 1.250 \\
5 & 2 & 35 & 110.59 & 159.231 & 152.388 & 6.843 & 4.298 \\
\hline
\end{tabular}

It appears that out of five runs, three runs were favoured the goal of the response (glycerol concentration) than the experimental results $(159.414 \mathrm{~g} / \mathrm{L}, 159.473 \mathrm{~g} / \mathrm{L}$ and $159.652 \mathrm{~g} / \mathrm{L})$. Hence, the optimum glycerol recovery from the pre-treatment process was at $\mathrm{pH} 2,35$ ${ }^{\circ} \mathrm{C}$, and $110.36 \mathrm{~g}$ of substrate. Under this condition, $159.312 \mathrm{~g} / \mathrm{L}$ of glycerol was recovered. The acidic condition is better for esterification process to get high concentration of glycerol. The best amount of mass substrate is important because high concentration of substrate can have saturated the solution and affects the reaction in esterification process for recovery of glycerol.

\section{Succinic acid production via anaerobic fermentation}

The effect of different substrate sources in the anaerobic fermentation of glycerol was investigated with batch fermentation using the medium that was supplemented with 19.67 
$\mathrm{g} / \mathrm{L}$ of glycerol for each sources of glycerol. The sample of succinic acid production was measured using high performance liquid chromatography (HPLC).

The fermentation result in terms of average succinic acid production from using treated glycerol from oleochemical sources was $0.66983 \mathrm{~g} / \mathrm{L}$. Meanwhile, fermentation using commercial glycerol produced $0.73337 \mathrm{~g} / \mathrm{L}$ of succinic acid. It can be concluded that the treated glycerol was suitable asthe medium for the growth of E.coli with comparable amount of succinic acid produced with commercial glycerol. Both treated and commercial glycerol offer carbon source for the microorganism in the medium. The use of commercial glycerol has the advantage by having higher purity of which resulted in greater production of succinic acid. HPLC results detected two unknown component or composition at 7.868 minute and 10.233 minute. Thus, reduces the purity of treated glycerol, yet, the difference of succinic acid generated between treated glycerol and commercial glycerol was only approximately $10 \%$. The study showed that the other composition besides glycerol did not affect the fermentation process to produce succinic acid and the difference error was less than $10 \%$.

\subsection{CONCLUSION}

Process optimisation has shown that the optimum condition for glycerol recovery was at $\mathrm{pH} 2,35^{\circ} \mathrm{C}$, and $110.36 \mathrm{~g}$ of substrate. With this optimum condition, $159.312 \mathrm{~g} / \mathrm{L}$ of glycerol was recovered. The use of treated glycerol and commercial glycerol significantly produced succinic acid by Escherichia coli type k-12. The highest amount of succinic acid obtained from treated glycerol was $0.66983 \mathrm{~g} / \mathrm{L}$ while commercial glycerol produced $0.73337 \mathrm{~g} / \mathrm{L}$. The percentage error between treated glycerol (glycerol residue) and commercial glycerol with regards to succinic acid production was $9.48 \%$, and the error between treated glycerol residue and treated glycerol pitch was $9.82 \%$.

\subsection{REFERENCES}

Agarwal, L., Isar, J., Meghwanshi, G.K., Saxena, R.K., 2007. Influence of environmental and nutritional factors on succinic acid production and enzymes of reverse tricarboxylic acid cycle from Enterococcus flavescens. Enzyme Microbial Technolology 40, 629-636.

Agarwal, L., Isar, J., Saxena, R.K., 2005. Rapid screening procedures for identification of succinic acid producers. J. Biochem. Biophys. Methods 63, 24-32.

Corona-González, R.I., Bories, A., González-Álvarez, V., Pelayo-Ortiz, C., 2008. Kinetic study of succinic acid production by Actinobacillus succinogenes ZT-130. Process Biochemistry 43, 1047-1053.

Darnoko, D., Cheryan, M., 2000. Kinetics of palm oil transesterification in a batch reactor. Journal of American Oil Chemist' Society. 77, 1263-1267.

Dikshit, P.K., Moholkar, V.S., 2016. Kinetic analysis of dihydroxyacetone production from crude glycerol by immobilized cells of Gluconobacter oxydans MTCC 904. Bioresource Technology 216, 948-957.

Hayyan, A., Alam, M.Z., Mirghani, M.E.S., Kabbashi, N.A., Hakimi, N.I.N.M., Siran, Y.M., Tahiruddin, S., 2011. Reduction of high content of free fatty acid in sludge palm oil via acid catalyst for biodiesel production. Fuel Process Technology 92, 920-924.

Hazimah, a H., Ooi, T.L., Salmiah, a, 2003. Recovery of Glycerol and Diglycerol From Glycerol Pitch Recovery of Glycerol and Diglycerol From Glycerol Pitch. Journal Oil Palm Residue. 15, 1-5.

Isar, J., Agarwal, L., Saran, S., Saxena, R.K., 2006a. A statistical method for enhancing the production of succinic acid from Escherichia coli under anaerobic conditions. Bioresource Technology. 97, 14431448.

Isar, J., Agarwal, L., Saran, S., Saxena, R.K., 2006b. Succinic acid production from Bacteroides fragilis: Process optimization and scale up in a bioreactor. Anaerobe 12, 231-237.

Lee, P.C., Lee, W.G., Lee, S.Y., Chang, H.N., Chang, Y.K., 2000. Fermentative Production of Succinic Acid from Glucose and Corn Steep Liquor by Anaerobiospirillum succiniciproducens. Biotechnology Bioprocess Engineering. 5, 379-381.

Rashid, U., Anwar, F., 2008. Production of biodiesel through optimized alkaline-catalyzed transesterification of rapeseed oil. Fuel 87, 265-273. 
Journal of Chemical Engineering and Industrial Biotechnology V2(2017)27-36

Song, H., Lee, S.Y., 2006. Production of succinic acid by bacterial fermentation. Enzyme Microbioly Technology. 39, 352-361.

Zeikus, J.G., Jain, M.K., Elankovan, P., 1999. Biotechnology of succinic acid production and markets for derived industrial products. Applied Microbiology Biotechnology. 51, 545-552. 